\title{
Catalysis of Diribonucleoside Monophosphate Cleavage by Water Soluble Copper(II) Complexes of Calix[4]arene Based Nitrogen Ligands
}

Roberta Cacciapaglia, ${ }^{\dagger}$ Alessandro Casnati, $\neq$ Luigi Mandolini, ${ }^{*},+$ David N. Reinhoudt,,, Riccardo Salvio, ${ }^{\dagger}$ Andrea Sartori, $\&$ Rocco Ungaro*,‡

Dipartimento di Chimica and IMC - CNR Sezione Meccanismi di Reazione, Università La Sapienza, Box 34 - Roma 62, 00185 Roma, Italy; Dipartimento di Chimica Organica e Industriale, Università degli Studi di Parma, V.le G. P. Usberti 17/A, 43100 Parma, Italy and Laboratory of Supramolecular Chemistry and Technology, MESA ${ }^{+}-$Research Institute, University of Twente, P.O. Box 217, 7500 AE Enschede, The Netherlands d.n.reinhoudt@tnw.utwente.nl; luigi.mandolini@uniroma1.it; rocco.ungaro@unipr.it

\section{Supporting Information}




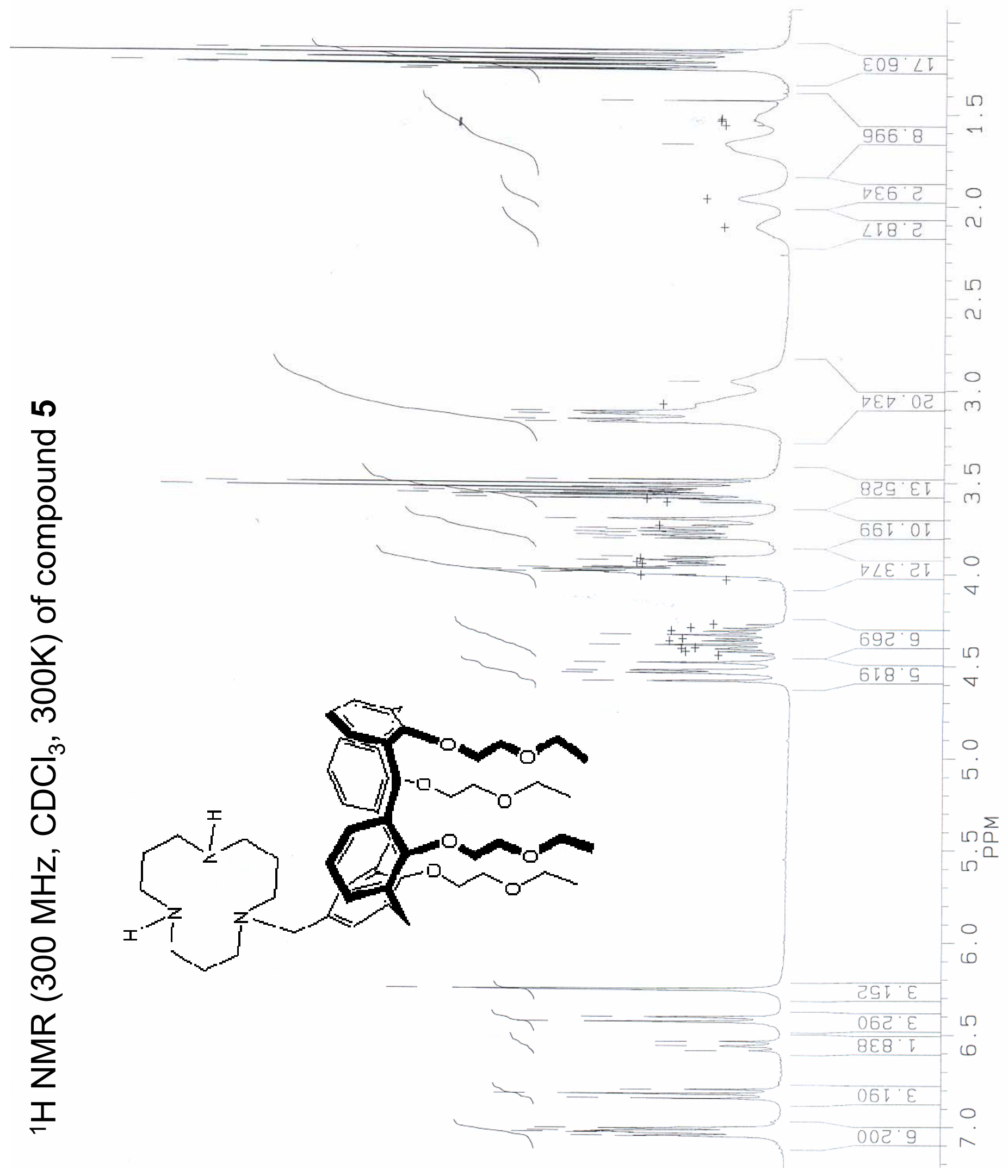

S2 


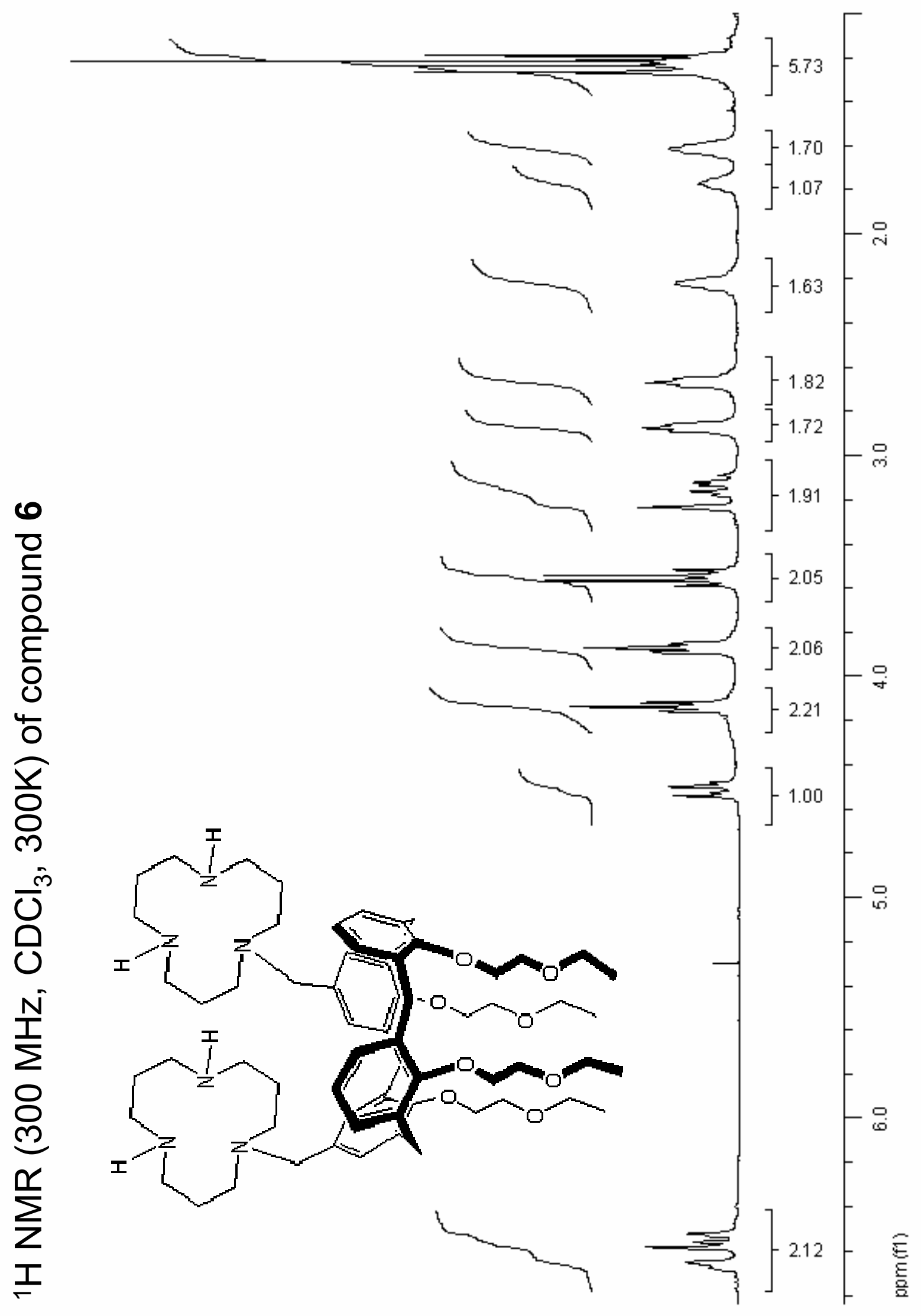




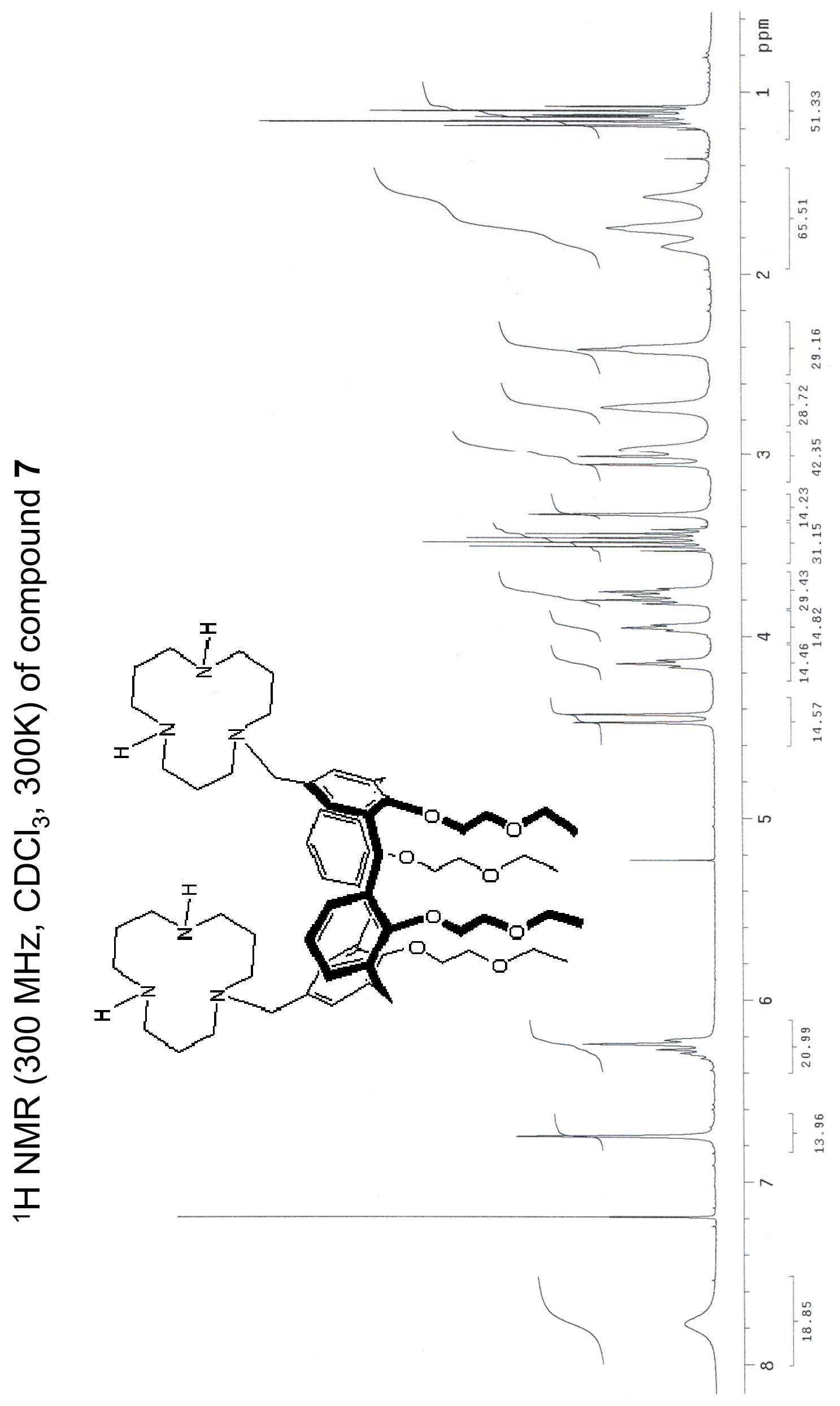




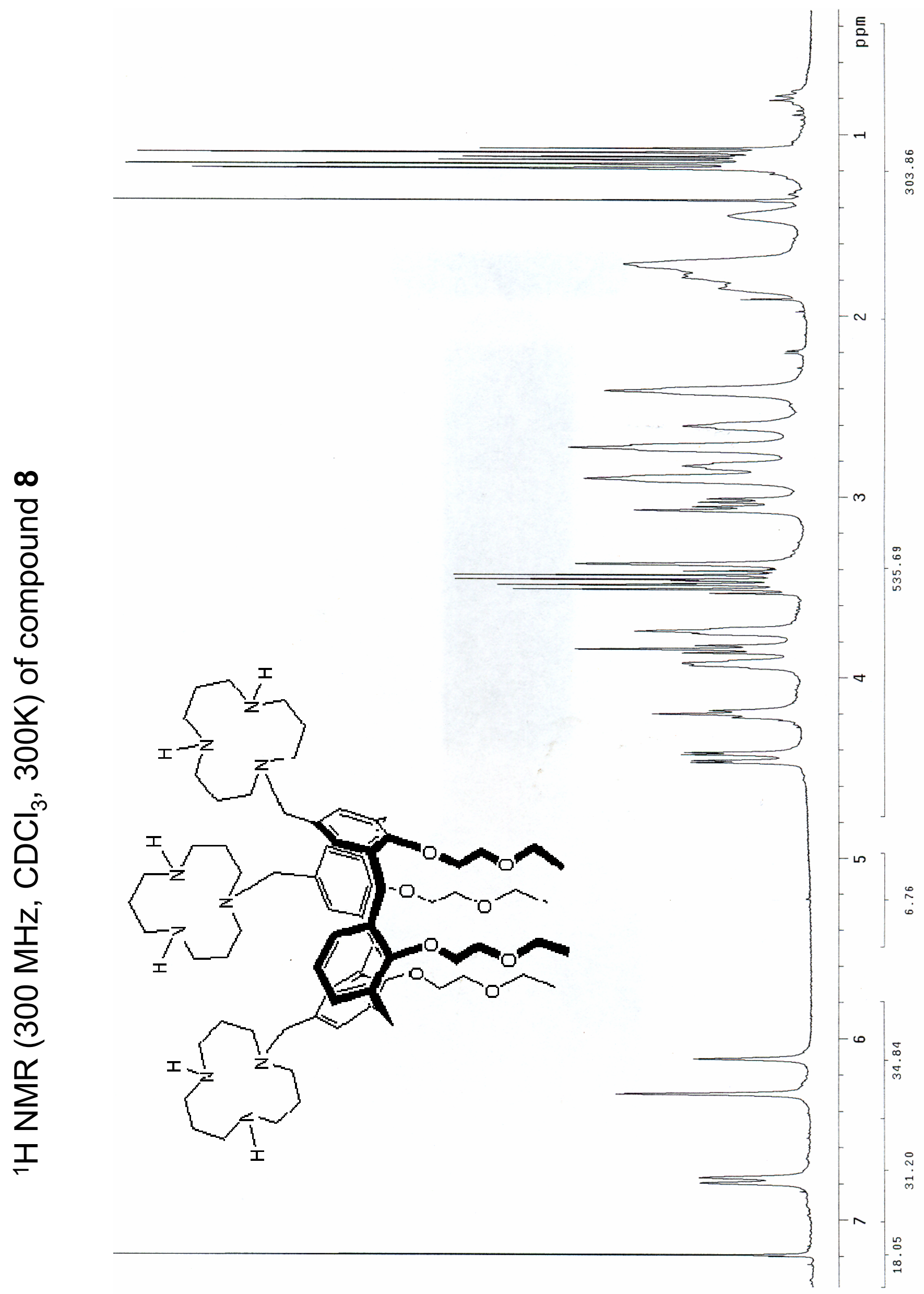




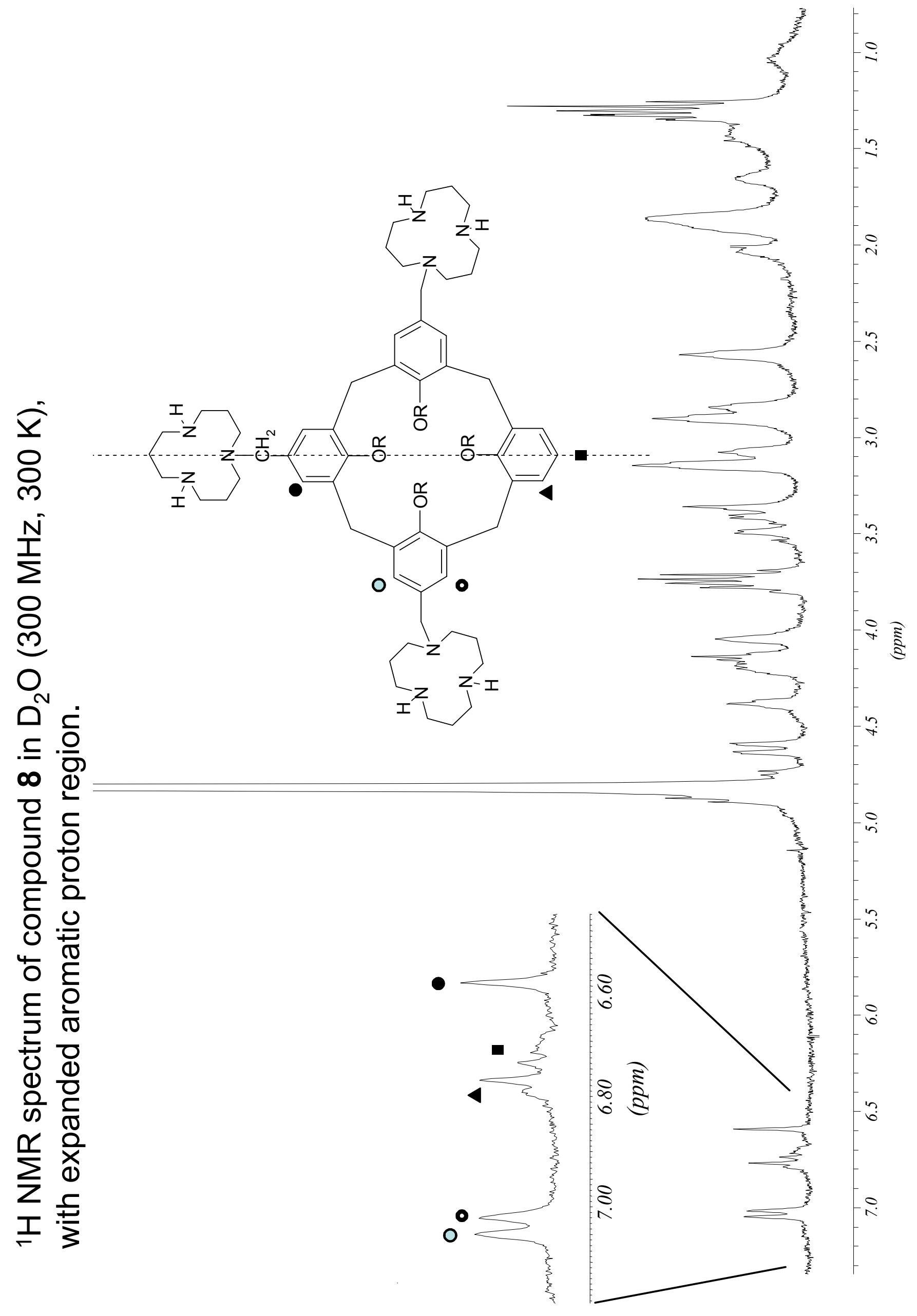

